The Journal of Animal \& Plant Sciences, 30(5): 2020, Page: 1319-1330

ISSN (print): 1018-7081; ISSN (online): 2309-8694

\title{
NEWLY RECORDED SPECIES AND SPATIO-TEMPORAL DISTRIBUTION OF RARELYCOLLECTED TRIBE ADESHINI (BRACONIDAE: BRACONINAE) FROM PAKISTAN
}

\author{
N. Nargis ${ }^{1 *}$, M. Naeem ${ }^{1}$, L. Vilhelmsen ${ }^{2}$, I. Bodlah ${ }^{1}$ and M.S. Nadeem ${ }^{3}$ \\ ${ }^{1}$ Insect Biosystematics and Ecology Group, Department of Entomology, Pir Mehr Ali Shah Arid Agriculture University, \\ Rawalpindi, Pakistan; ${ }^{2}$ Natural History Museum of Denmark, SCIENCE, University of Copenhagen, Universitetsparken \\ 15, DK-2100, Denmark; ${ }^{3}$ Department of Zoology, Pir Mehr Ali Shah Arid Agriculture University, Rawalpindi, Pakistan. \\ ${ }^{*}$ Corresponding author's email: baneenaac@yahoo.com
}

\begin{abstract}
Adesha Cameron 1912, Indadesha Quicke 1986 and Aneuradesha Quicke 1986 are rarely found genera previously recorded only from India and Malaysia. In the present study these genera are reported for the first time from Pakistan, represented by four species: Indadesha achterbergi Quicke, Aneuradesha harleyi Quicke, Adesha albolineata Cameron and Adesha acuta Quicke collected from four host plants viz., guava (Psidium guajava), citrus (Citrus reticulata), sugarcane (Saccharum officinarum) and maize (Zea mays). Effects of ecological factors and weather conditions on the distribution of recorded taxa were also studied from Islamabad, Rawalpindi and Chakwal. The study reveals that members of the tribe Adeshini are more likely to be found from April to August and with low rainfall. An illustrated key to genera and species from Pakistan, host plants, abundance, distribution and spatio-temporal graphical representation of Adeshini related to weather parameters are also provided.
\end{abstract}

Keywords: Taxonomy; Hymenoptera; Braconinae; new records; distribution; Pakistan.

https://doi.org/10.36899/JAPS.2020.5.0150

Published online June 25, 2020

\section{INTRODUCTION}

Braconinae 1812, with 200 genera and 2500 described species is one of the largest subfamilies in the family Braconidae, order Hymenoptera. Most members of this subfamily act as idiobiont ectoparasitoids of various members of order Coleoptera, Diptera, Lepidoptera and Hymenoptera, of which, some are important pests (Shaw and Huddleston, 1991; Quicke, 2015). The tribe Adeshini is comprised of seven genera: Adesha Cameron 1912, Adeshoides van Achterberg 1983, Africadasha Quicke 1986, Spinadesha Quicke 1988, Aneuradesha Quicke and Polaszek 2000, Furcadesha Quicke 1986 and Indadesha Quicke 1986. The tribe comprises of only 13 described, rarely encountered species mainly reported from tropical regions in the Oriental, Afrotropical and Indo-Australian realms (van Achterberg, 1983; Quicke, 1986, 1988; Quicke and Ingram, 1993; Quicke and Polaszek, 2000; Wang et al., 2006; Liu et al., 2007; Ranjith et al., 2017).

Members of Adeshini tribe are distinct and can be differentiated from other tribes by combination of the following characters: scapus sub-globose, shorter on ventral side than dorsal; parallel-sided basal flagellomeres; fore-wing 2 nd sub marginal cell almost parallel-sided or narrow on distal side both forewing veins $\mathrm{Cu} 1 \mathrm{a}$ and 2-Cu1 arising at same level resulting in vein $\mathrm{Culb}$ being longer than vein 3-Cul; hind wing, vein r-m short; propodeum having complete medial longitudinal carina short (van Achterberg, 1983; Quicke, 1986).

Adesha is the type genus for Adeshini tribe. Adesha albolineata Cameron, 1912, from Malaysia was the first described species, yet it was re-described by van Achterberg (1983). Thereafter two more species were added i.e. Adesha acuta Quicke, 1986, (from the Malay Peninsula) and Adesha narendrani Ranjith et al., 2017 (from southern India). The two genera Aneuradesha Quicke and Indadesha Quicke are represented by single species viz. Aneuradesha harleyi Quicke and Polaszek, 2000 and Indadesha achterbergi Quicke, 1986, from India. Very little information regarding the biology of members of tribe Adeshini is known except for Aneuradesha harleyi which is reported as a parasitic wasp of Asmangulia cuspidata Maulik, a pest of rice and sugarcane in India and Indonesia, and Adesha albolineata Cameron which is a parasitoid of coconut leaf miner beetle Promecotheca cumingi Baly (Quicke and Polaszek, 2000).

Climatic parameters including temperature, rainfall and relative humidity have a great impact over insect population and it influences their distribution as well (Siswanto et al., 2008). However, taxonomic and ecological studies on braconids in relation to climatic parameters are very few (Fernandez-Triana et al., 2011). The distribution of parasitoid wasps may be affected by relative humidity, rainfall and temperature ranges 
throughout the year (Sorribas et al., 2010). Variation in climatic factors may result in changing population dynamics of species and ecological system stability (Meisner et al., 2014).

Despite their multiple importance as stated above, No significant work has been done in Pakistan exploring Braconinae fauna. In this lieu present study was planned to study effect of climate parameters (temperature, rainfall and relative humidity) over seasonal abundance Adeshini braconids, for the first time in Pakistan.

\section{MATERIALS AND METHODS}

Spatio-temporal distribution of members of Adeshini was determined in selected sites during 2017-18 in the Pothwar tract of Punjab. Collection was done from Islamabad district: NARC research farm $\left(33^{\circ} 44.811 \mathrm{~N}\right.$ 073 07.809E, $491 \mathrm{~m}$ ), agricultural lands (Sugarcane, maize, fodder crops, cucurbitaceae, guava, citrus, pomegraint, olive orchards); Chakwal district: Kallar Kahar $\left(32^{\circ} 47.734 \mathrm{~N} 72^{\circ} 43.779 \mathrm{E}, 711 \mathrm{~m}\right)$, agricultural land and rangeland habitats (citrus, olive and loquat orchards); Chakwal city $\left(32^{\circ} 56.638 \mathrm{~N} 072^{\circ} 35.811 \mathrm{E}, 446\right.$ $\mathrm{m})$, maize fields; Rawalpindi district: Poultry Research Institute (PRI) $\left(33^{\circ} 39.211 \mathrm{~N} 073^{\circ} 04.697 \mathrm{E}, 510 \mathrm{~m}\right)$, agricultural land habitat (citrus orchard, maize); Koont Farm $\left(33^{\circ} 07.013 \mathrm{~N} 073^{\circ} 00.694 \mathrm{E} 447 \mathrm{~m}\right)$, maize fields.

Collection was done using sweep net and malaise traps emptied every two weeks. Ethanolpreserved specimens were stored in the Biosystematics Entomology Laboratory, PMAS-AAUR, Pakistan. Specimens were later dried using Hexamethyldisilazane (HMDS) and mounted on card points. Specimens were examined using Labomed CZM6 stereozoom microscope (10X / 22 W.F) and photographs were taken by Visionary Digital stacking system in the Natural History Museum of Denmark, University of Copenhagen. After taking measurements of the specimen's body parts via micrometry, all specimens were deposited in the Entomology Department of PMAS- AAUR, Pakistan. Month-wise climatological data of rainfall $(\mathrm{mm})$ and temperature $\left({ }^{\circ} \mathrm{C}\right)$ was taken from the Pakistan Meteorological Department of selected sites. Distributional map for recorded taxa (Fig. 6) was plotted by Q-GIS 2.13 .

Terminology: For morphological terms in illustrations, we follow van Achterberg $(1974,1979)$ for wing venation. For body sculpturing, Eady (1968), Harris (1979) and Quicke (1986) were followed.

\section{RESULTS}

A total of 42 specimens of tribe Adeshini were collected from Pothwar region belonging to 4 species under 3 genera.

\section{(a) Taxonomy \\ Family Braconidae \\ Subfamily Braconinae Nees, 1812 \\ Tribe Adeshini Achterberg, 1983}

Key and diagnostic characters of genera and species are given as under:

\section{Key to genera of Tribe Adeshini Achterberg}

1. Propodeum with complete medial longitudinal carina (Figs. 1D, 3D and 4D); vein Culb present in forewing (Figs. 1B, 3B and 4B) ....

Propodeum with median-longitudinal carina extending more or less half the length (Fig. 2C); vein $\mathrm{Culb}$ absent in forewing (Fig. 2B).............................Aneuradesha Quicke 2. Laterope on $1^{\text {st }}$ metasomal tergum absent (Fig. 1D); T-2 without a medial longitudinal carina (Fig. 1D); mesoscutum without a medio-longitudinal groove; mesosternum coriaceous.....................Indadesha Quicke

Laterope on $1^{\text {st }}$ metasomal tergum welldeveloped (Fig. 3D and 4D); T-2 with almost complete medial longitudinal carina (Fig. 3D and 4D); mesoscutum with medio-longitudinal groove; mesosternum smooth

Adesha Cameron

Genus Indadesha Quicke, 1986 (new record to Pakistan)

Diagnosis: Antennal scape not baso-dorsally swollen; mesoscutum smooth and hairless on anterior side; veins $\mathrm{C}+\mathrm{SC}+\mathrm{R}$ and $1-\mathrm{SR}$ angled above $47^{\circ}$; laterope on $1^{\text {st }}$ metasomal tergum absent (Fig. 1D); $2^{\text {nd }}$ metasomal suture crenulated; $5^{\text {th }}$ metasomal tergite with prominent lateral semicircular emarginations (Fig. 1E).

Distribution: Oriental (India) and Pakistan (present study).

\section{Indadesha achterbergi Quicke, 1986 (Fig. 1A-E)}

Material examined: Islamabad, $33^{\circ} 44.811 \mathrm{~N}$, 07307.809E, 491m, 2 ô ô, 15.iv.2017, 5우, 14.v.2017, leg. Nargis; Chakwal, 32॰47.734N, 72॰43.779E, $711 \mathrm{~m}, 2$ 우, 16.vi.2017, leg. Nargis, 2 우 and 1ठ, 16.viii.2017, leg. Naeem.

Diagnosis: Mean female body length $2.9 \mathrm{~mm}(2.6-2.10$ $\mathrm{mm}, \mathrm{n}=9)$; mean fore-wing length $3.0 \mathrm{~mm}(2.8-3.2 \mathrm{~mm}$, $\mathrm{n}=9)$; mean male body length $2.65 \mathrm{~mm}(2.5-2.8 \mathrm{~mm}$, $\mathrm{n}=3)$; mean forewing length $2.8 \mathrm{~mm}(2.7-2.9 \mathrm{~mm}, \mathrm{n}=3)$; antenna bearing 38 flagellomeres; Antennal sockets not protruding anteriorly; first flagellomere $1 \mathrm{X}$ length of $2^{\text {nd }}$ flagellomere; mesosoma $1.6 \mathrm{X}$ longer than high; 
metasomal sculpture coarse anteriorly; first metasomal tergite $0.63 \mathrm{X}$ as long as wide posteriorly; posterior tergites almost equally reticulate-rugulose; fifth tergite smooth anteriorly to transverse with sub-basal depression at postero-lateral margins; ovipositor sheath $0.13 \mathrm{X}$ length of forewing; antennae usually distally black, basally brown; head including legs and body yellowish light brown except hind tarsi, medial part of $1^{\text {st }}$ metasomal tergite and second to $4^{\text {th }}$ tergites sub-medially infuscated except brownish yellow mid-longitudinal line; wings with venation brown; ovipositor sheath black.

Host Plant: S. officinarum and Z. mays.

Distribution: India, Pakistan. Indadesha achterbergi is hereby first time reported for Pakistan.

\section{Genus Aneuradesha Quicke and Polaszek, 2000 (new record to Pakistan)}

Diagnosis: Flagellomeres usually longer than wide; notauli usually deeply impressed anteriorly and slightly depressed, punctuate part in posterior third of mesoscutum; forewing without vein Culb (Fig. 2B); propodeal longitudinal carina reduced (Fig. 2C); second metasomal suture crenulated.

Distribution: Oriental (India) and Pakistan (present study).

Aneuradesha harleyi Quicke and Polaszek, 2000 (Fig. 2 A-E)

Material examined: Islamabad, $\quad 33^{\circ} 44.811 \mathrm{~N}$,

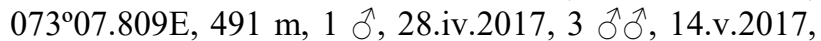
leg. Nargis; Rawalpindi, 3339.211 N, 07304.697 E, 510

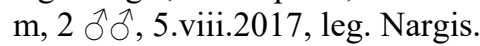

Diagnosis: Mean male body length $2.56 \mathrm{~mm}$ (2.5-2.7 $\mathrm{mm}, \mathrm{n}=6$ ); mean forewing length $2.51 \mathrm{~mm}(2.4-2.6 \mathrm{~mm}$, $\mathrm{n}=6)$; antennae bearing 32 flagellomeres; first flagellomere $1.1 \mathrm{X}$ length of 2nd flagellomere; mesosoma $1.15 \mathrm{X}$ longer than high; scutellum having small distinct pit with fine crenulate scutellar sulcus; vein $1 \mathrm{cu}-\mathrm{a}$ of forewing slightly postfurcal; hind wing base uniformly setose; first and $2^{\text {nd }}$ metasomal tergites with granulose reticulate rugose sculpture (Fig. 2E); first metasomal tergite $0.83 \mathrm{X}$ as long as wide posteriorly; $5^{\text {th }}$ metasomal tergite having lateral semicircular emarginations (Fig. 2D); yellowish brown in color except flagellomeres, with blackish marks on median part of $1^{\text {st }}$ metasomal tergite, medio-basal part of $2^{\text {nd }}$ metasomal tergite and also on $3^{\text {rd }}$ and $4^{\text {th }}$ metasomal tergites.

Host Plant: S. officinarum and C. reticulata.

Host: A. cuspidate (Quicke and Polaszek, 2000).

Distribution: India and Pakistan. Aneuradesha harleyi is hereby first time reported for Pakistan.
Genus Adesha Cameron, 1912 (new record to Pakistan)

Diagnosis: Head and mesosoma usually smooth; antennae bearing more than 50 flagellomeres; mesoscutum heavily setose, with well-developed notauli anteriorly; propodeum with median longitudinal carina (Figs 3D and 4D); forewing veins $\mathrm{C}+\mathrm{SC}+\mathrm{R}$ and $1-\mathrm{SR}$ angle below $45^{\circ}$; vein $1-\mathrm{SR}+\mathrm{M}$ straight; claws with basal lobes absent; metasoma rugose; second metasomal tergite having a medial carina usually reaching middle of tergite (Figs. 3D and 4D); fifth metasomal tergite posterior margin with well-developed semicircular emarginations (Figs. 3E and 4E).

Distribution: Oriental (India and Malaysia) and Pakistan (present study).

\section{Key to species of Adesha Cameron}

1. Fifth metasomal tergite with postero-lateral emarginations shallow and poorly developed (Fig. 3E); scutellum usually dark brown (Fig. 3C)......A. albolineata

Fifth metasomal tergite with postero-lateral emarginations well-developed (Fig. 4E); scutellum usually yellow-brown (Fig. 4C).................. acuta

\section{Adesha albolineata Cameron, 1912 (Fig 3 A-E)}

Material examined: Islamabad, $33^{\circ} 44.811 \mathrm{~N}$, 07307.809E, $491 \mathrm{~m}, 3$ 우, 29.v.2017, 4 우우,

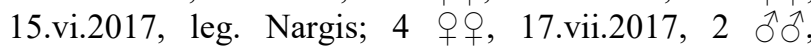
29.viii.2017, leg. Naeem.

Diagnosis: Mean female body length $3.78 \mathrm{~mm}$ (3.60-3.80 $\mathrm{mm}, \mathrm{n}=11)$; mean fore-wing length $2.9 \mathrm{~mm}(2.78-3.1$ $\mathrm{mm}, \mathrm{n}=11)$; mean male body length $3.57 \mathrm{~mm}(3.45-3.70$ $\mathrm{mm}, \mathrm{n}=2)$; mean forewing length $2.42 \mathrm{~mm}(2.35-2.50$ $\mathrm{mm}, \mathrm{n}=2)$; first flagellomere $1 \mathrm{X}$ length of $2 \mathrm{nd}$ flagellomere; antennal sockets weakly protruding anteriorly; frons slightly convex, smooth; face weakly convex, smooth; mesoscutum rather convex, reduced mid-longitudinal groove on medial lobe (Figure 3C); 2 $\mathrm{SR}, 3-\mathrm{SR}$ and $\mathrm{r}$ veins uniformly thick; first metasomal tergite $0.63 \mathrm{X}$ as long as wide posteriorly, medial area coarsely reticulate; second metasomal tergite bearing mid-basal quadrate part rugose, median longitudinal extending carina well beyond middle of tergite (Fig. 3D); $5^{\text {th }}$ metasomal tergite having semicircular emarginations shallow (Fig. 3E); ovipositor sheath $0.09 \mathrm{X}$ length of forewing, hypopygium apically truncate; antennae, largely dorsal part of head, meso- and metasoma brownish yellow; metasoma yellowish laterally and $5^{\text {th }}$ tergite apically; wing subhyaline with pterostigma, wing venation brown; hind tibia, tarsi and ovipositor sheath dark brown to black.

Host: P. cumingi Baly (Quicke and Polaszek, 2000).

Host plants: P. guajava. 
Distribution: Malaysia and Pakistan. A. albolineata is hereby first time reported for Pakistan.

\section{Adesha acuta Quicke, 1986 (Fig. 4 A-E)}

Material examined: Islamabad, $33^{\circ} 44.811 \mathrm{~N}$, $073^{\circ} 07.809 \mathrm{E}, 491 \mathrm{~m}, 1 \delta^{\lambda}$ and 3 우, 15.iv.2017, leg. Nargis; Chakwal, $32^{\circ} 56.638 \mathrm{~N}, 072^{\circ} 35.811 \mathrm{E}, 446 \mathrm{~m}, 2$ $\hat{\mathrm{O}} \mathrm{O}$ and 4 우, 30.v.2017, leg. Nargis; Rawalpindi, $33^{\circ} 07.013 \mathrm{~N}, 073^{\circ} 00.694 \mathrm{E}, 447 \mathrm{~m}, 2$ 우우 5.viii.2017, leg. Nargis.

Diagnosis: Mean female body length $3.12 \mathrm{~mm}$ (2.92-3.15 $\mathrm{mm}, \mathrm{n}=9)$; mean fore-wing length $2.92 \mathrm{~mm}(2.85-3.14$ $\mathrm{mm}, \mathrm{n}=9)$; mean male body length $2.85 \mathrm{~mm}(2.75-2.90$ $\mathrm{mm}, \mathrm{n}=3)$; mean forewing length $2.62 \mathrm{~mm}(2.51-2.70$ $\mathrm{mm}, \mathrm{n}=3$ ); first flagellomere $1.25 \mathrm{X}$ length of $2 \mathrm{nd}$ flagellomere; mesosoma $1.45 \mathrm{X}$ longer than high; mesoscutum with well developed medial longitudinal groove posteriorly; first metasomal tergite $1.32 \mathrm{X}$ as long as wide posteriorly with coarsely rugose raised area; second metasomal tergite rugose with mid-longitudinal carina extending middle of tergite, with mid-basal triangular part (Fig. 4D); fifth metasomal tergite with pronounced semicircular emarginations (Fig. 4E); colour brown yellowish except for brown antennae, venation and pronotal groove anterolaterally, middle lobe midanteriorly and largely lateral lobes of mesoscutum, $1^{\text {st }}$ tergite raised median area, between sublateral furrows of $2^{\text {nd }}$ tergite and ovipositor sheath black; mid, hind leg tarsi and tibia slightly infuscate.

Host: P. cumingi Baly (Quicke and Polaszek, 2000).

Host plant: $P$. guajava and $Z$. mays.

Distribution: Malaysia and Pakistan. A. acuta is hereby first time reported for Pakistan.

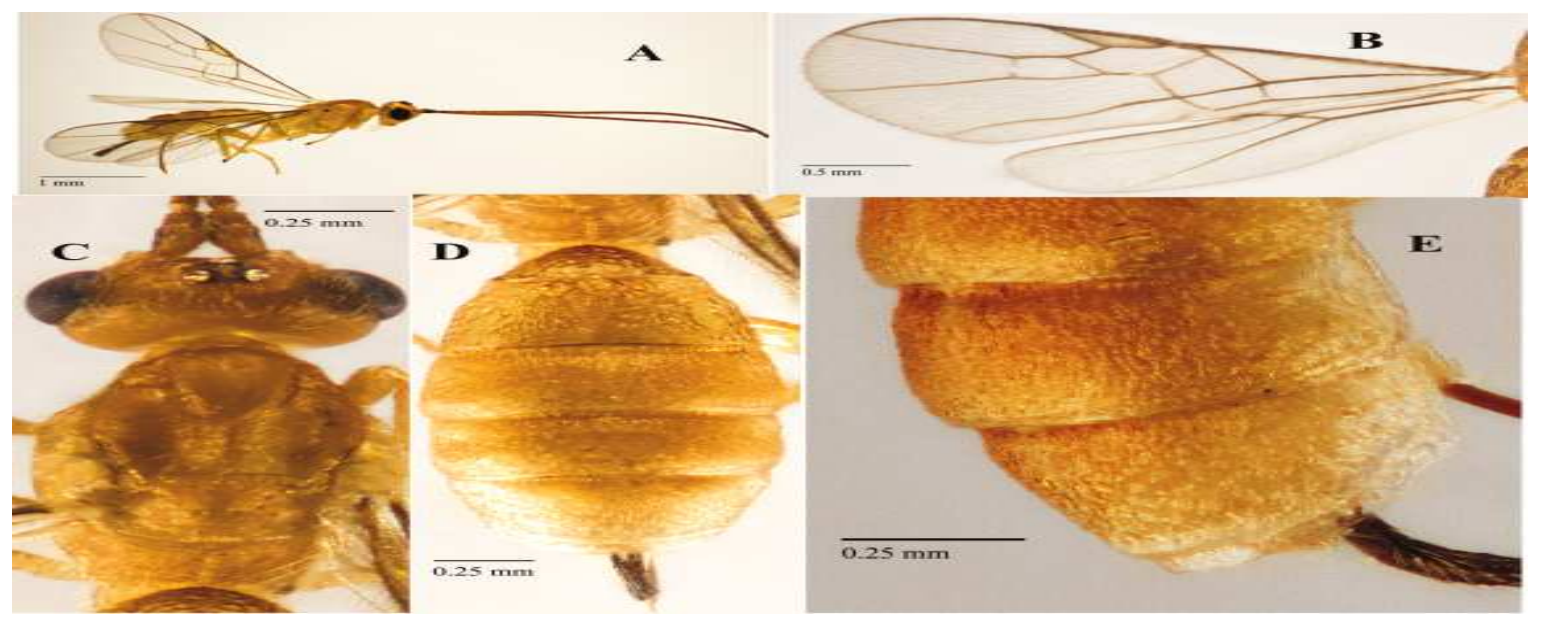

Figure 1. A-E Indadesha achterbergi Quicke; A- Habitus, B- Wings, C- Mesosoma and propodeum (dorsal view), D- Metasoma and propodeum (dorsal view), E- Metasoma showing $5^{\text {th }}$ metasomal tergite (lateral view).
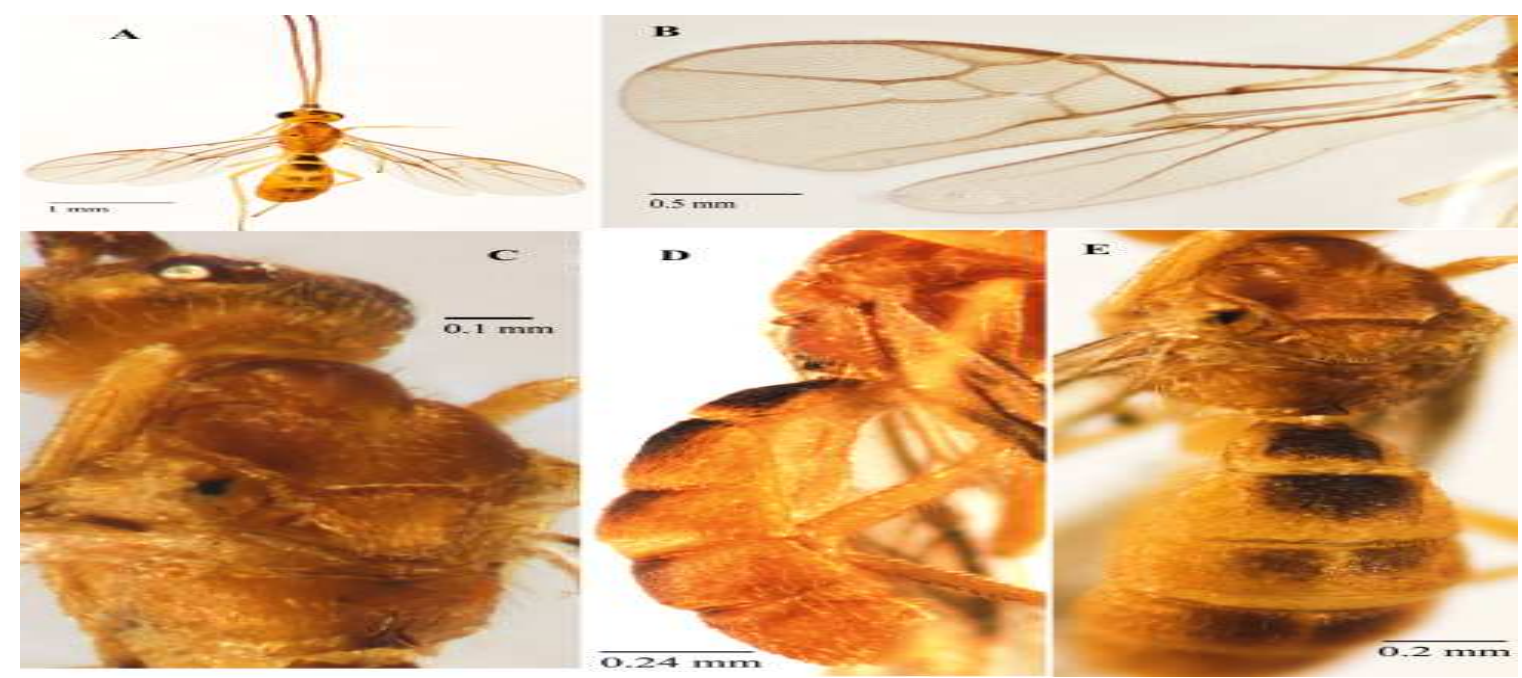

Figure 2. A-E Aneuradesha harleyi Quicke; A- Habitus, B- Wings, C- Mesosoma and propodeum, D- Metasoma showing $5^{\text {th }}$ metasomal tergite (lateral view), E- Mesosoma and $1^{\text {st }}, 2^{\text {nd }}$ and $3^{\text {rd }}$ metasomal tergites (dorsal view). 


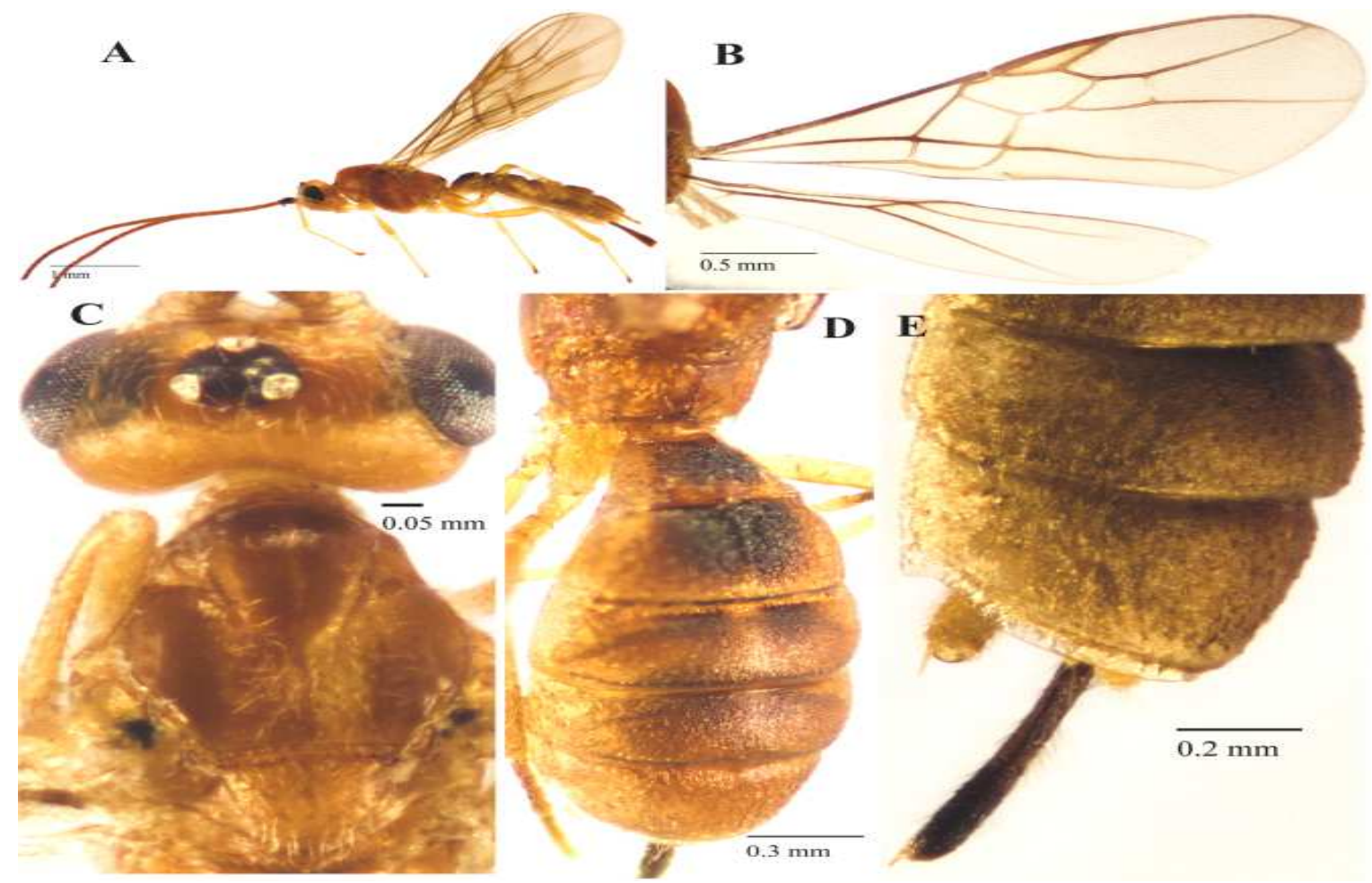

Figure 3. A-E Adesha albolineata Cameron; A- Habitus, B- Wings, C- Mesosoma (dorsal view), D- propodeum and metasoma (dorsal view), E- Metasoma showing $5^{\text {th }}$ metasomal tergite (lateral view).

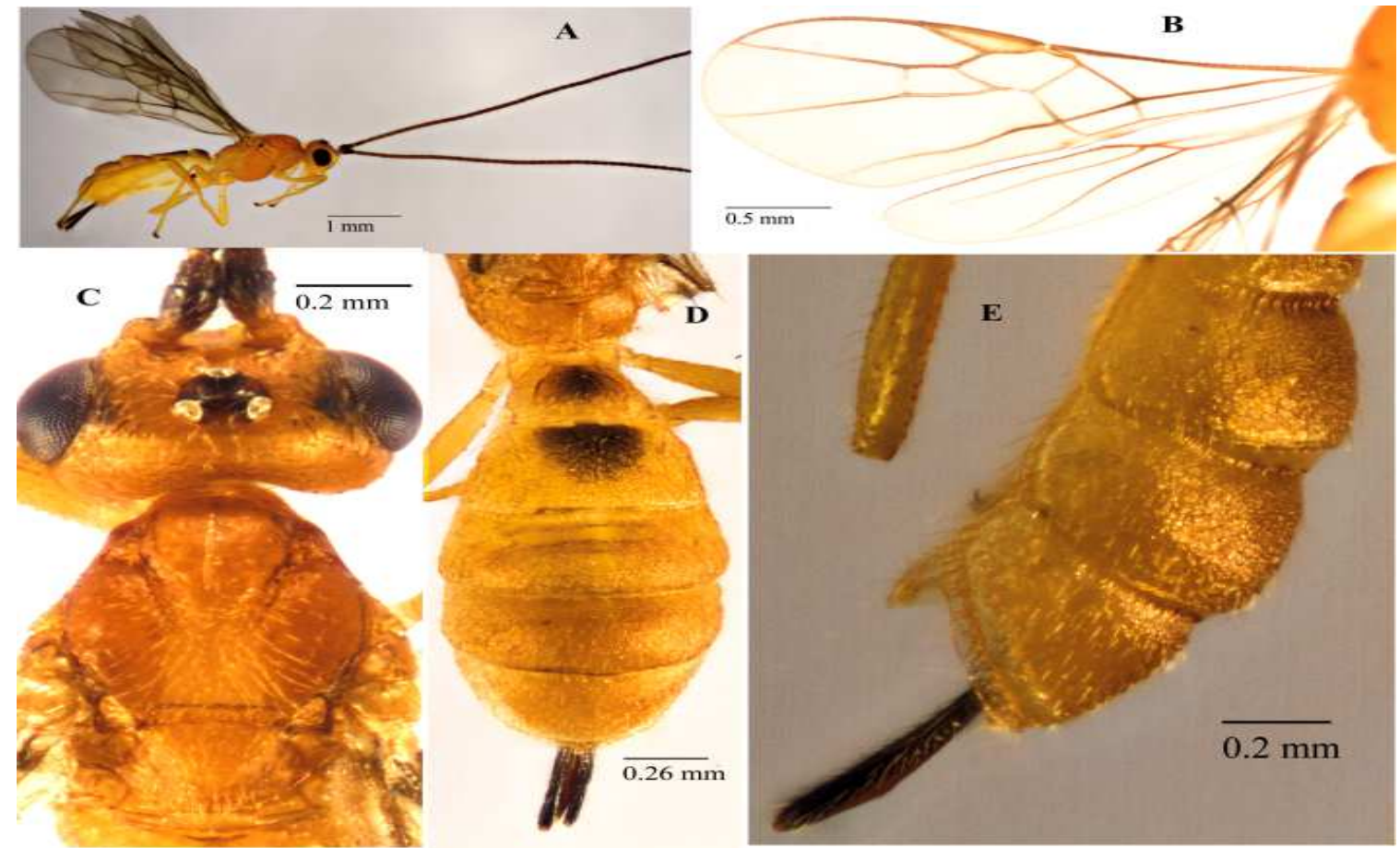

Figure 4. A-E Adesha acuta Quicke; A- Habitus, B- Wings. C- Mesosoma (dorsal view), D- propodeum and metasoma (dorsal view), E- $5^{\text {th }}$ metasomal tergite (lateral view).

(b) Ecological parameters of Adeshini

Details for recorded taxa: The occurrence of Adeshini from five sampling sites in Pothwar region is shown in
Fig. 6. From collected specimens, 26\% (11 specimens) belong to Indadesha achterbergi, 14\% (6 specimens) belong to Aneuradesha harleyi, 31\% (13 specimens) 
belong to Adesha albolineata and 29\% (12 specimens) belong to Adesha acuta (Fig. 5).

Spatio-temporal graphical representation in Islamabad: Twenty-eight specimens of four species, $I$. achterbergi, A. harleyi, A. albolineata and A. acuta were collected from agricultural habitats: sugarcane fields, maize fields and guava orchards. Members of tribe Adeshini were not found from January- March, July and September-December (Fig. 7). Abundance and diversity of Adeshini parasitoids was observed in the months of April, May, June and August at an average temperature of $26.5^{\circ} \mathrm{C}$, comparatively less rainfall, humidity, as compared to other months of the study period at this location.

Spatio-temporal graphical representation in Rawalpindi: Four specimens of two species $A$. harleyi and $A$. acuta were collected from predominantly agricultural land type habitat viz., maize fields and citrus orchard. Presence of recorded taxa was observed in the months of May and September (Fig. 8) at an average temperature of $30^{\circ} \mathrm{C}$, less rainfall, at sampling site as compared to the remaining study periods. Adeshini declined to zero in the remaining months of the year (Fig. 8).

Spatio-temporal graphical representation in Chakwal: Ten specimens of two species viz., $I$. achterbergi and A. acuta were collected from agricultural land type habitat including citrus orchards and olive orchards. Recorded taxa were collected in the dry months of June and September at an average temperature of $29.6^{\circ} \mathrm{C}$. Members of tribe Adeshini declined to zero in remaining months of the year (Fig. 9).

\section{DISCUSSION}

In the present study, a total of 42 specimens of tribe Adeshini were recorded from Pothwar region which revealed four species in three genera. All these are new additions to the braconid fauna of Pakistan. Among these A. harleyi was previously reported as a parasitoid of $A$. cuspidate, (rice and sugarcane pest) in India and Indonesia while $A$. albolineata was documented as parasitoid of $P$. cumingi (coconut leaf miner beetle) in Malaysia (Quicke and Polaszek, 2000). During current study, $A$.harleyi was recorded from fields of sugarcane and citrus orchards, I. achterbergi from sugarcane and maize fields, $A$. albolineata from guava orchards and $A$. acuta, from orchards of guava, olive and maize fields. These species can possibly parasitize pests of guava, olive, citrus, maize and sugarcane; yet it need further study. No data on the actual host organisms of Adeshini available from Pakistan and thus further taxonomic work and exploration of host associations is crucial for evaluating applicability of members of Adeshini in pest management in different parts of the country.

Parasitoids are mainly dependent upon their hosts, host plant physiology and are thus highly susceptible to climate change. The spatio-temporal study indicates that species of Adeshini are mostly observed in the months of April, May, June, August and September. This also might be due to the presence of host, suitable microclimate, macroclimate and food resources in these months. The results are in agreement with Wolda (1988). In addition to hosts, some additional resources e.g., adult food, mating sites etc might also be suitable in the collection period. The results are in line to Dyer and Landis (1996). Braconid wasps e.g., Apanteles spp., Meteorus spp., Chelonus spp., Agathis spp., Cotesia spp., Microplitis spp., Diaeretiella spp., Apanteles spp., Cotesia spp. of different vegetables belonging to family Leguminoseae, Solanaceae, Malvaceae, Cruciferae and Cucurbitaceae were reported in the months of February, March, April, June, August and September due to the availability of their hosts (Halder et al., 2018). Members of Adeshini were mostly recorded at sampling location (NARC) in district Islamabad because there is more diversity of crops (sugarcane, maize, cucurbitaceae vegetables, fodder crops) and orchards (guava, citrus, pomegranate, olive) as compared to sampling location (PRI) and Koont farm, district Rawalpindi (citrus orchard, maize field) and Kallar Kahar farm, district Chakwal (citrus, olive and loquat orchards) and maiz fields. This might be because of more diversity of crops, the height of grasses, weeds and ground cover at sampling sites in Islamabad as compared to other sampling localities. Our results are also in agreement with Stamps and Linit (1997), Thomson and Hoffmann (2010), Smith et al. (2015) and Andow et al. (2016). In the Pothwar Region, the occurrence of recorded taxa is inversely related to rainfall, might be because of survival strategy at low humidity and in search of their hosts in the absence of rains. Similar results for parasitoid wasps have been observed by others (Fernandez-Triana et al., 2011; Aranda and Graciolli, 2015). It is also observed that recorded taxa usually found at an average minimum temperature range of $22^{\circ} \mathrm{C}$ to a maximum temperature range of $32^{\circ} \mathrm{C}$. The results are in line with Akhtar et al. (2010) that emergence of aphid parasitoids of family Braconidae was high at maximum temperature of $30.66^{\circ} \mathrm{C}$ and at minimum temperature $14.80^{\circ} \mathrm{C}$. Some members of family Braconidae preferred $25^{\circ} \mathrm{C}$ as observed by Zamani et al. (2007). Same results were observed by other workers relating to parasitoid distribution which is usually higher at high temperature during warm months of the year (Sorribas et al.,2010). Braconid wasps, e.g., Cotesia species are strongly affected by climate change and among these, Cotesia sesamiae is most prevalent in regions of higher rainfall (Mohyuddin and Greathead, 1970) whereas Cotesia 
flavipes is mostly observed in warm regions with less rainfall (Songa et al., 2001; Niyibigira, 2003).

Site wise collection

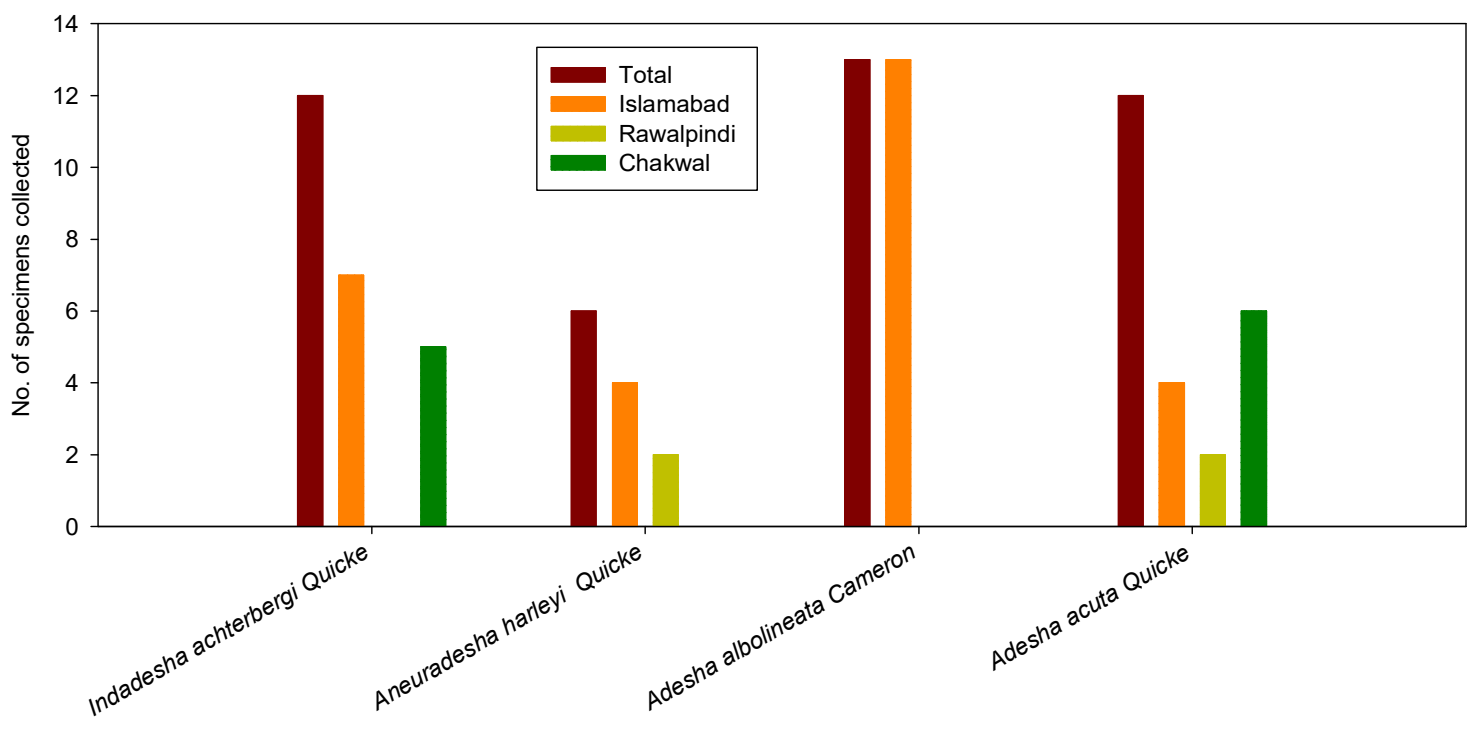

Species

Figure 5. Abundance of Adeshini species in Pothwar plateau Pakistan during 2017.

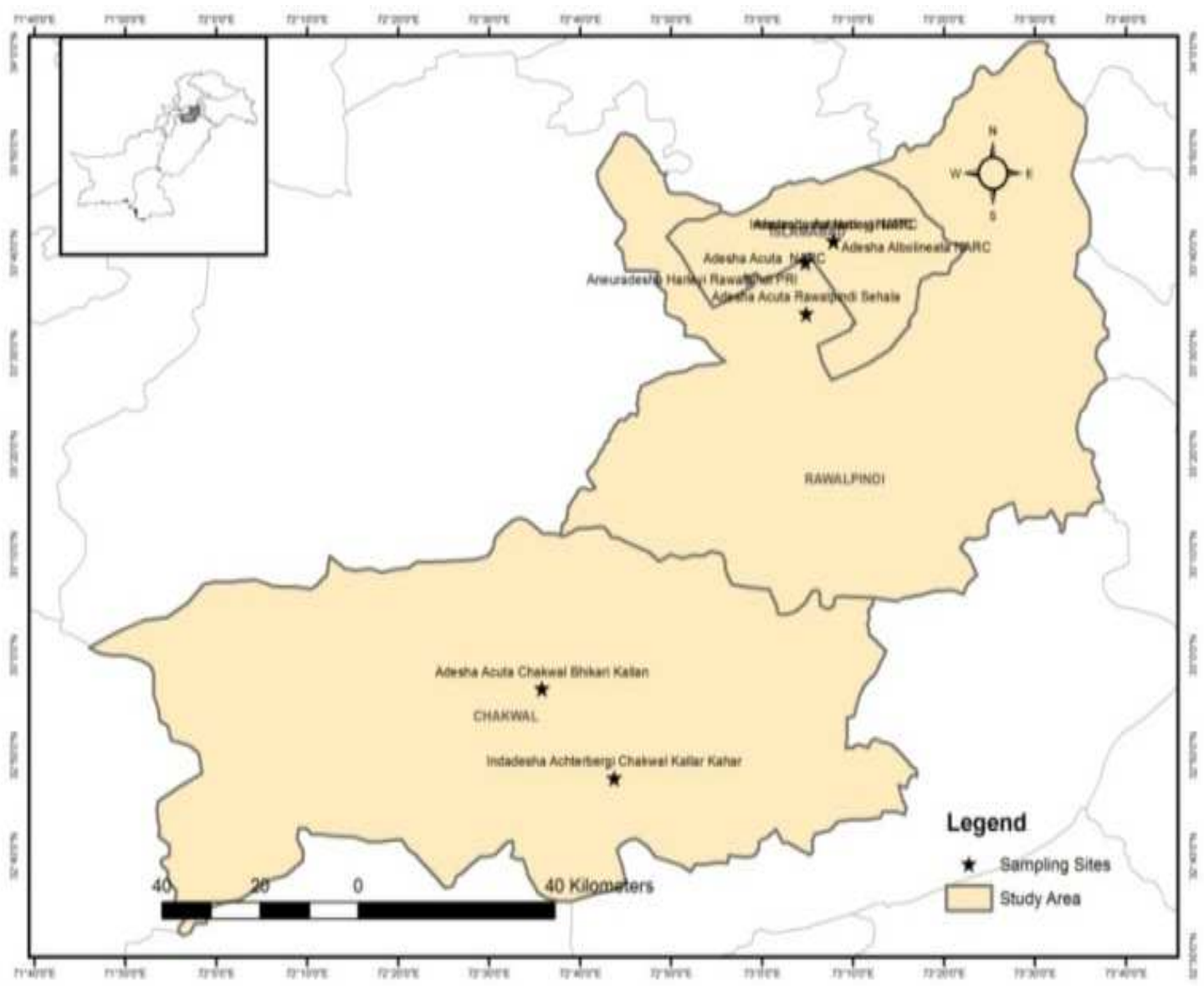

Figure 6. A distributional map of Adeshini species in Pothwar region. 


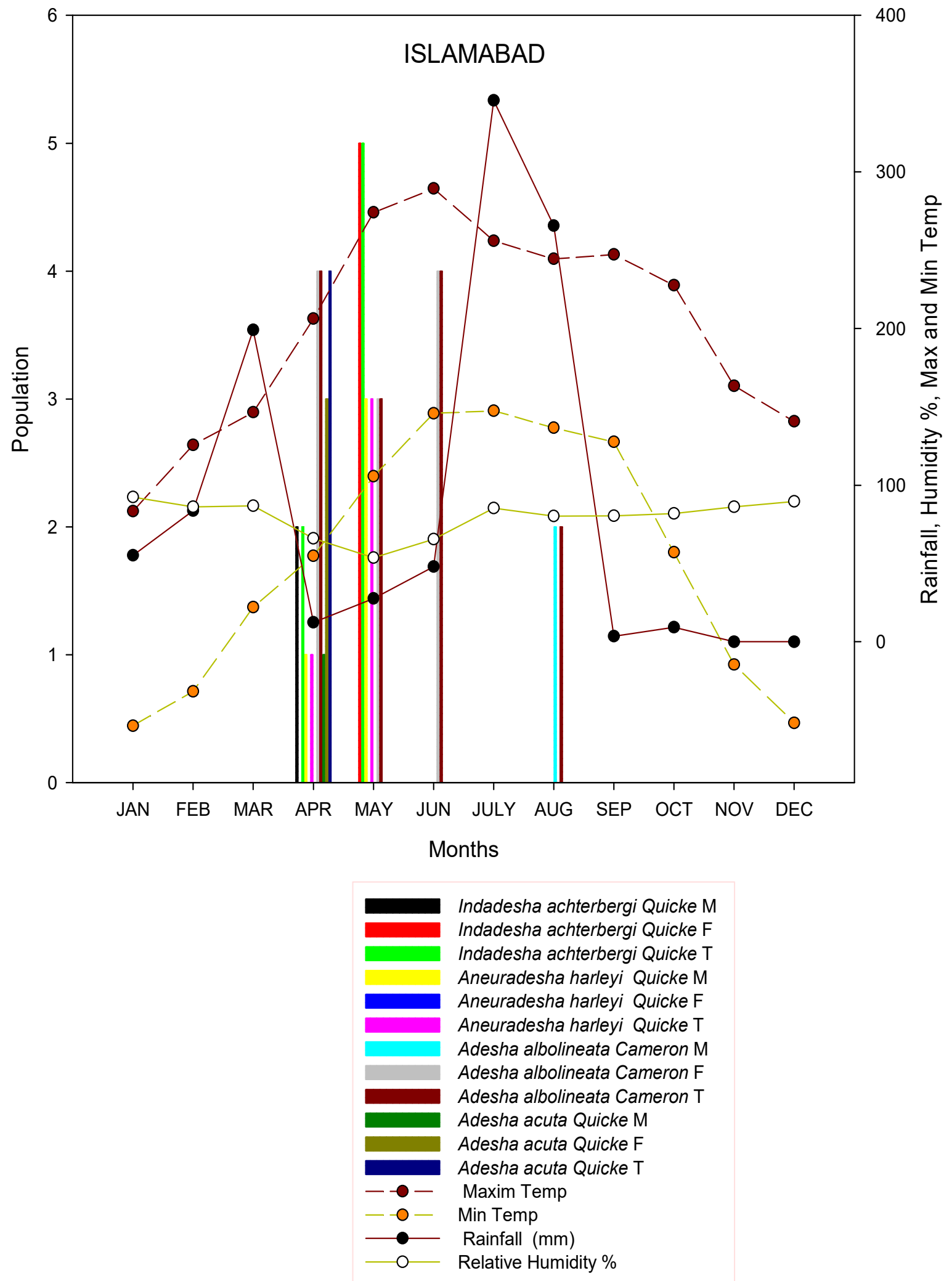

Figure 7. Spatio-temporal graphical representation of Adeshini in relation to weather parameters in Islamabad. 


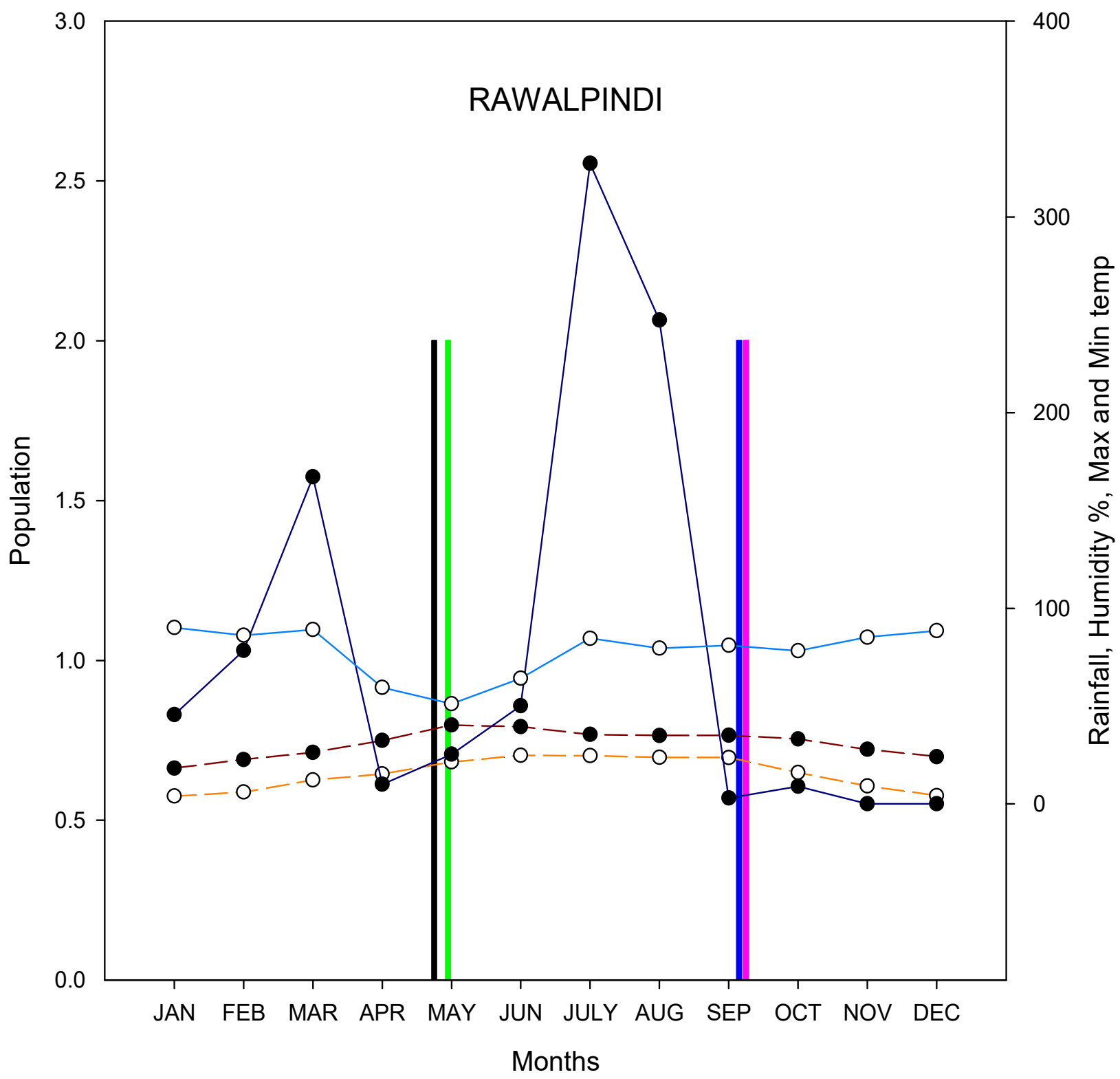

\begin{tabular}{|c|c|}
\hline & Aneuradesha harleyi Quicke M \\
\hline & Aneuradesha harleyi Quicke F \\
\hline & Aneuradesha harleyi Quicke T \\
\hline & Adesha acuta Quicke M \\
\hline & Adesha acuta Quicke F \\
\hline & Adesha acuta Quicke T \\
\hline$-\rightarrow-$ & Max Temp \\
\hline$-0-$ & Min Temp \\
\hline 0 & Rainfall (mm) \\
\hline - & Relative Humidity \% \\
\hline
\end{tabular}

Figure 8. Spatio-temporal graphical representation of Adeshini in relation to weather parameters in Rawalpindi. 

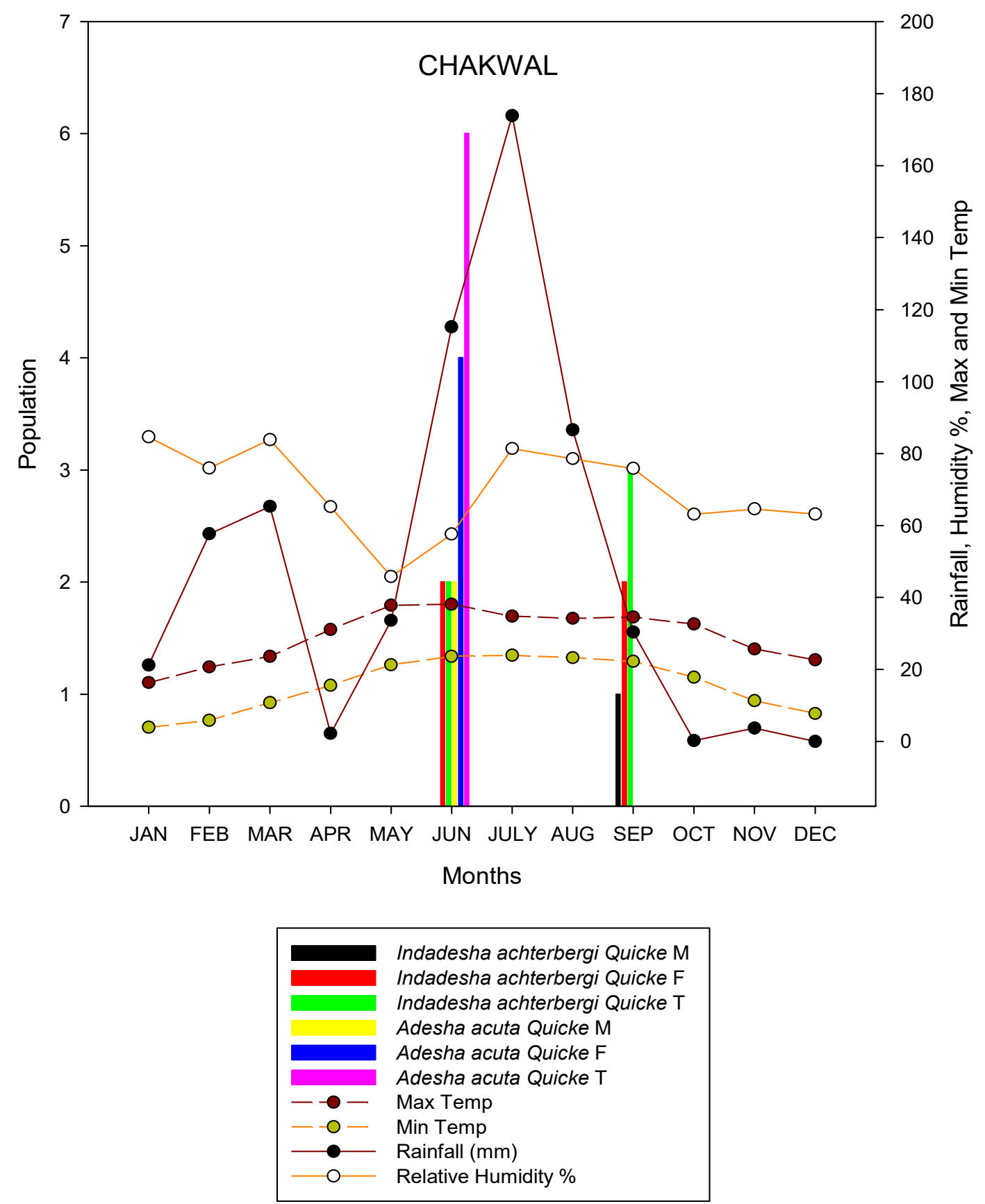

Figure 9. Spatio-temporal graphical representation of Adeshini in relation to weather parameters in Chakwal.

Acknowledgments: We are thankful to Mr. Anders Illum and Mr. Mikkel Høegh Post (Natural History Museum Denmark, University of Copenhagen) for technical assistance. We are also thankful to Prof. John Richard Schrock, (Emporia State University USA) for English proof reading of this manuscript. This study was supported by Higher Education Commission of Pakistan.

\section{REFERENCES}

Achterberg, C.V. (1974). The features of the petiolar segment in some Braconidae (Hym.). Entomol. Ber. 34: 213-214.

Achterberg, C.V. (1979). A revision of the subfamily Zelinaeauct. (Hymenoptera: Braconidae). Tijkschr. Ent. 122: 241-259. 
Achterberg, C.V. (1983). Six new genera of Braconinae from the Afrotropical region (Hymenoptera, Braconidae). Tijdschr. Entomol. 126: 175-202.

Akhtar, M.S., D. Dey, M.K. Usmani, and R. Choudhury (2010). Seasonal abundance of Diaretiella rapae (Mintosh) (Braconidae: Aphidiinae) parasitizing Lipaphis Erysimi (Kaltenbach) (Hemiptera: Aphididae) in Brassica juncea variety Pusa Bold. Mun. Ent. Zool. 5(2): 692-696.

Andow, D.A., J.P. Harmon, and N.A. Schellhorn (2016). Using cultural practices to enhance insect pest control by natural enemies. CRC Press; Florida (USA). 157-181 pp

Aranda, R. and G. Graciolli (2015). Spatial-temporal distribution of the Hymenoptera in the Brazilian savanna and the effects of habitat heterogeneity on these patterns. J. Insect Conserv. 19(6): 11731187.

Dyer, L.E. and D.A. Landis (1996). Effects of habitat, temperature, and sugar availability on longevity of Eriborus terebrans (Hymenoptera: Ichneumonidae). Environ. Entomol. 25(5): 1192-1201.

Eady, R.D. (1968). Some illustrations of microsculpture in the Hymenoptera. Proc. Royal Entomol. Soc. A. 43: 66-72. http://dx.doi.org/10.1111/j.13653032.1968.tb01029.x.

Fernandez-Triana, J., M.A. Smith, C. Boudreault, H. Goulet, P.D. Hebert, A.C. Smith, and R. Roughley (2011). A poorly known high-latitude parasitoid wasp community: unexpected diversity and dramatic changes through time. PLoSONE. 6(8): e23719.

Halder, J., A. Rai, D. Dey, and B. Singh (2018). Abundance of important parasitoids in the vegetable ecosystem and their prospects in integrated pest management. J. Entomol. Zool. Stud. 6(4): 762-769.

Harris, R.A. (1979). A glossary of surface sculpturing. California Department of Food and Agriculture, Bureau of Entomology. Occas. Pap. Entomol. 28: 1-31.

Liu, J.J., J.H. Chen, and J.Q. Yang (2007). The genus Furcadesha Quicke (Hymenoptera, Braconidae, Braconinae) in China, with description of two new species. J. Anim. Taxon. 32(3): 574-578.

Meisner, M.H., J.P. Harmon, and A.R. Ives (2014). Temperature effects on long-term population dynamics in a parasitoid-host system. Ecol. Monogr. 84(3): 457-476.

Mohyuddin, A. and D. Greathead (1970). An annoted list of the parasites of graminaceous stem borers in East Africa, with a discussion of their potential in biological control. Entomophaga. 15(3): 241274.
Niyibigira, E.I. (2003). Genetic variability in Cotesia flavipes and its importance in biological control of lepidopteron stem borers. Ph.D. thesis. Deptt. of Entomol., Wageningen Univ., Netherland.

Quicke, D.L.J. (1986). A revision of the Adeshini van Achterberg with descriptions of three new genera from the Palaeotropics (Insecta, Hymenoptera, Braconidae). Zool. Scr. 15(3): 265-274. http://dx.doi.org/10.1111/j.14636409.1986.tb00228.x.

Quicke, D.L.J. (1988). A new genus and species of Adeshini (Hymenoptera: Braconidae, Braconinae) from Thailand. Entomol. Mag. 124: 203-205.

Quicke, D.L.J. and S.N. Ingram (1993). Braconine wasps of Australia. Mem. Queensl. Mus. 33(1): 299336.

Quicke, D.L.J. and A. Polaszek (2000). A new genus and first host records, for the Adeshini: parasitoids of hispine beetles (Braconidae: Braconinae; Coleoptera: Chrysomelidae). J. Hymenopt. Res. 9(1): 104-107.

Quicke, D.L.J. (2015). The braconid and ichneumonid parasitoid wasps: biology, systematics, evolution and ecology. John Wiley and Sons; Chichester (UK).

Ranjith, A.P., J.T. Jenning, and M. Naseer (2017). Review of the rarely collected genus Adesha Cameron (Hymenoptera: Braconidae, Braconinae) with description of a new species from Southern India. Insect Diver. Taxon. 11: 97-110.

Shaw, M. and T. Huddleson (1991). Classification and biology of braconid wasps (Hymenoptera Braconidae). $7^{\text {th }}$ Ed. Royal Entomological Societies; London. 54-55 pp

Siswanto, R.M., O. Dzolkhifli, and K. Elna (2008). Population fluctuation of Helopeltis antonii Signoret on Cashew Anacardium occidentalle L. in Java Indonesia Pertanika. J. Trop. Agric. Sci. 31(2): 191-196.

Smith, I.M., A.A. Hoffmann, and L.J. Thomson (2015). Ground cover and floral resources in shelterbelts increase the abundance of beneficial hymenopteran families. Agr. Forest Entomol. 17(2): 120-128.

Songa, J., W. Overholt, J. Mueke, and R. Okello (2001). Colonisation of Cotesia flavipes (Hymenoptera: Braconidae) in stem borers in the semi-arid Eastern Province of Kenya. Int. J. Trop. Insect Sci. 21(4): 289-295.

Sorribas, J., R. Rodriguez, and F. Garcia-Mari (2010). Parasitoid competitive displacement and coexistence in citrus agro ecosystems: linking species distribution with climate. Ecol. Appl. 20(4): 1101-1113. 
Stamps, W. and M. Linit (1997). Plant diversity and arthropod communities: Implications for temperate agroforestry. Agrofor. Syst. 39(1): 73.

Thomson, L.J. and A.A. Hoffmann (2010). Natural enemy responses and pest control: importance of local vegetation. Biol. Control. 52(2): 160-166.

Wang, Y.P., X.X. Chen, and J.H. He (2006). The discovery of the genus Spinadesha (Hymenoptera, Braconidae, Braconinae) in
China, with description of a new species. Biologia. 61(2): 145-147.

Wolda, H. (1988). Insect seasonality: why?. Annu. Rev. Ecol. Syst. 19(1): 1-18.

Zamani, A.A., A. Talebi, Y. Fathipour, and V. Baniameri (2007). Effect of temperature on life history of Aphidius colemani and Aphidius matricariae (Hymenoptera: Braconidae), two parasitoids of Aphis gossypii and Myzus persicae (Homoptera: Aphididae). Environ. Entomol. 36(2): 263-271. 